\title{
A CASE SERIES OF EUCALYPTUS OIL-INDUCED SEIZURES
}

\author{
SINDHU SHANMUGAM ${ }^{1}$, MELINA I SAHAY ${ }^{1}$, PEARLSY GRACE RAJAN ${ }^{2}$, SRIRAM DK ${ }^{3}$, MELVIN GEORGE ${ }^{1 *}$
}

${ }^{1}$ Department of Clinical Research, Hindu Mission Hospital, Chennai, Tamil Nadu, India. ${ }^{2}$ Department of General Medicine, Hindu Mission Hospital, Chennai, Tamil Nadu, India. ${ }^{3}$ Department of Diabetology and Endocrinology, Hindu Mission Hospital, Chennai, Tamil Nadu, India. Email: drmelvingeorge@hindumissionhospital.org

Received: 25 May 2020, Revised and Accepted: 27 July 2020

ABSTRACT

Eucalyptus oil (EO) is an essential oil which has been used as a traditional remedy in upper respiratory tract infection. It contains approximately $90 \%$ cineole and is readily available worldwide in over-the-counter cough drops, liniments, toothpaste, mouthwashes, cold preparations, and hair lice remover. EO-induced adverse drug reaction is rare in both adults and children. The signs and symptoms of EO poisoning are CNS depression, hypotension, tachycardia, epigastric pain, nausea, vomiting, and contact dermatitis. Symptom onset is usually rapid and resolves within $24 \mathrm{~h}$. We report the case series of four adult patients with EO-induced seizure in India, who inhaled EO for common cold and presented to the critical care with single first attack of generalized tonic-clonic seizures. On further evaluation, none of them had a family background of seizures/febrile seizures. EEG and brain MRI were found to be normal in all patients. All the patients were managed with anti-epileptic drugs and standard supportive care. All medical practitioners should be aware of the toxic effects of EO, a common OTC medication used in Indian households. Warning labels may be attached on EO comprised products.

Keywords: Eucalyptus oil, Poisoning, Seizures, OTC medication.

(C) 2020 The Authors. Published by Innovare Academic Sciences Pvt Ltd. This is an open access article under the CC BY license (http://creativecommons. org/licenses/by/4. 0/) DOI: http://dx.doi.org/10.22159/ajpcr.2020.v13i9.38443

\section{INTRODUCTION}

Epilepsy is a chronic non-communicable neurological disorder about 50 million people of all age have affected. Globally, onset of new cases is 5 million people per year [1]. Recent publications have provided robust figures regarding the incidence of sudden unexpected death in epilepsy patients with comparable rates of 1.1-1.2/1000 patients' years [2]. Seizures are the most common adverse action of drug intoxication, nearly $9 \%$ of cases occur due to drug or poison. Seizures are changes in the brain electrical activity either due to inadequate inhibitory influences nor excessive excitatory stimulation. The neurotransmitters and neuropeptides involved in mechanism of action. Mostly, the drug-induced seizures are self-limiting [3]. Eucalyptus oil (EO) is an essential oil extracted from Eucalyptus globulus, is a Myrtaceae plant family, native to Australia. EO has been used as a traditional remedy to upper respiratory tract infection, gastritis, and diabetes [4]. Chemical constituents of EO are 1,8-cineole and other compounds are monoterpenes (d-limonene, $\alpha$-pinene, $\beta$-pinene, and $\mathrm{p}$-cymene), alkaloids, eucalyptin, phenols, flavonoids 6,8-dimethylkaempferol3,7-dimethyl ether, oleanolic acid (2,3-dihydroxy-urs-12-en-28-oic acid), 8-desmethyl-eucalyptin, tannins, terpenoid phenolaldehydes, 2'6'-dihydroxy-3'-methyl-4'-methoxy-dihydrochalcone, and verbenone, a monoterpene bicyclic ketone [5]. The pharmacological activities of EO include antimicrobial, antihyperglycemic, anthelmintic, anti-viral, antihistaminic, and anti-inflammatory properties [5]. These volatile oils are found in many over-the-counter cough drops, liniments, toothpaste, mouthwashes, cold preparations, and hair lice remover and additionally used in transdermal drug delivery to enhance the penetration of minoxidil, zidovudine, and valsartan [6]. The public may not be aware of the potentially toxic effects of these oils and products if they are inhaled or ingested orally at higher concentrations. The signs and symptoms of EO poisoning are CNS depression, hypotension, tachycardia, epigastric pain, nausea, vomiting, and contact dermatitis. Symptom onset is usually rapid (within 5-10 min) and resolves within $24 \mathrm{~h}$ [7]. In this report, we present a case series of EO-induced seizures. Written informed consent was obtained from the patients for publication of this case report.

\section{DESCRIPTION OF CASES}

A 21-year-old male admitted to the emergency department with a single episode of a generalized tonic-clonic seizure. He also had uprolling of the eyeball, one episode of vomiting, headache, and generalized weakness. The patient had a fever and nasal congestion with nasal block for a day. He sought to relieve his symptoms with home remedies by application of 6-7 drops of oil on his handkerchief. Following this, he kept inhaling the oil 3-4 times by covering his nose with the same kerchief. Within a short while, he lost his balance and fell down. He had clonic movements for $5 \mathrm{~min}$, postictal confusion and nausea on presentation to the hospital. This was described by his relative accompanying him. On investigation, the patient had no previous history of seizures and did not have febrile seizures in childhood. There was no family background of seizure attacks. He had never inhaled EO in the past. His brain MRI was normal and the EEG report was also normal. He was given injection fosphenytoin $150 \mathrm{mg}$ IV route twice daily for 2 days along with other supportive treatment and was discharged after 2 days with an advice to continue anti-epileptic drugs for 1 month. During the follow-up for 6 months, no recurrence of seizure was observed. The patient was advised to stop the anti-epileptic drugs after a month. The causes of seizure were probably due to an increased cellular hyperexcitability induced by chemical compounds (cineole) in the EO.

Case 2

A 25-year-old male patient presented with one episode of a generalized tonic-clonic seizure. He had a lateral tongue bite with giddiness. The patient had inhaled the vapors of EO that was mixed in boiling water. He lost consciousness and had tonic posturing of all four limbs followed by clonic movements for $1 \mathrm{~min}$. He had no previous history of a seizure attack. Family history revealed that his young brother had the same complaint 1 year ago. The treatment was started with intravenous levetiracetam $1000 \mathrm{mg}$ (BD). On the next day, brain MRI and EEG were performed and reports are normal. The patient was continued with the same anti-epileptic drug for the next 2 days. He did not have any recurrent episodes of seizures. He was discharged on levetiracetam 500 mg twice daily for a month. After a month of follow-up, he was observed to be asymptomatic. 


\section{Case 3}

A 31-year-old male patient presented with one episode of generalized tonic-clonic seizure, postictal drowsiness with nausea in the emergency department. The patient had steam inhalation with EO for 3 min before the seizure attack. He had nasal congestion for 2 days with headache. He had no history of seizure attack and had no family history. The treatment was started with Intravenous levetiracetam 1000 mg (BD). Brain MRI and EEG reports revealed no abnormalities. The patient was discharged with medical advice on levetiracetam $500 \mathrm{mg}$ twice daily for a month. After a month of follow-up, he was found to be asymptomatic.

\section{Case 4}

A 37-year-old male patient presented with an episode of generalized tonic-clonic seizures with generalized weakness. Within $5 \mathrm{~min}$ of steam inhalation with EO, he had a seizure attack and remained drowsy for 30 min. His brain MRI and EEG were normal. The patient received levetiracetam $1000 \mathrm{mg}(\mathrm{BD})$ and was advised to continue antiepileptic drugs for 2 months. The patient was not willing to continue the medication. He was discharged after 2 days with patient counseling.

\section{DISCUSSION}

EO is a volatile oil obtained by rectifying the leaves of E. globulus. Australian Aboriginals use it as a traditional medicine for the treatment of body pains, sinus congestion, fever, and cold $[8,9]$. Dennis Considen and John White, surgeons on the first fleet, distilled EO in 1788 [10]. The active constituents are monoterpenes 1, 8-cineole (eucalyptol), which comprises nearly $70 \%$. It is readily available in many over-the-counter medications as cough drops, liniments, toothpaste, mouthwashes, and cold preparation slice remover and additionally used in transdermal drug delivery to enhance the penetration of minoxidil, zidovudine, and valsartan [6]. The reason behind the adverse effect of EO may be hydrocyanic acid which is highly toxic and may cause nausea, vomiting, drowsiness, seizures, coma, and at leads to death [11]. Such an adverse reaction induced by EO case was first found in Kerala on 1898 [12]. Similar case is reported in the U.K on 1911 [13]. In Toronto, Canada, they performed a retrospective analysis on EO poisoning over a period from December 1995 to March 1997. They found 233 cases of EO-induced adverse reaction which were reported [14]. Likewise, 42 cases of EO ingestion in children under 14 years of age were identified in a defined population between July 1, 1984, and June 30, 1991, in the Southeast, Queensland, by Webb and Pitt in December 1992 [15]. In 2011, New Zealand, Waldman explained 4-year girl with tonicclonic attack due to external application of EO and more recently in 2019 Sitaraman and Rao posted a reports and emergency measures taken for a 17-month-old female infant from New Delhi, India $[6,16]$. Thus, the incorrect usage of essential oil and other OTC medicinal substances is remarked as safe by people and most importantly they are an imbalance in the availability of qualified doctors in rural areas of India. This problem was prominently highlighted in a report on the status of the health workforce in India based on data obtained from the 2001 census published by the World Health Organization in 2016 [17]. The people in the rural area remained underserved, heavily rely on OTC self-treatment, unqualified practitioners' myths were observed and this may cause an increase in the rate of dangerous poisoning cases in India. Under this scenario, health workers should try to familiarize themselves with local usage patterns of home remedies, accordingly counsel parents and caregivers about the dangers inherent in their incorrect usage. In general, all health workers including physicians, paramedical, and traditional caregivers could undertake to actively provide such counseling to members of their local community.

\section{CONCLUSION}

This case series describes the seizure inducing property of EO and the importance of disseminating this information among the health care workers so that the public can be dissuaded from their usage. Although EO-induced seizure has a low incidence rate, one should keep this as a potential cause of seizures in any patient presenting to the hospital with a single episode of seizures and a recent history of taking any overthe-counter medication for rhinitis.

\section{CONFLICTS OF INTEREST}

The author declared that there are no conflicts of interest related to this study.

\section{AUTHORS' FUNDING}

Nil.

\section{ETHICAL STATEMENT}

Ethical approval was not applicable for case report in our institution.

\section{REFERENCES}

1. World Health Organization. Epilepsy. Geneva: World Health Organization; 2019. Available from: https://www.who.int/news-room/ fact-sheets/detail/epilepsy.

2. Ryvlin P. Update on seizure disorders. Curr Opin Neurol 2019;32:181-2.

3. Chen HY, Albertson TE, Olson KR. Treatment of drug-induced seizures. Br J Clin Pharmacol 2016;81:412-9.

4. Jun YS, Kang P, Min SS, Lee JM, Kim HK, Seol GH. Effect of eucalyptus oil inhalation on pain and inflammatory responses after total knee replacement: A randomized clinical trial. Evid Based Complement Alternat Med 2013;2013:502727.

5. Dhakad AK, Pandey VV, Beg S, Rawat JM, Singh A. Biological, medicinal and toxicological significance of Eucalyptus leaf essential oil: A review. J Sci Food Agric 2018;98:833-48

6. Waldman N. Seizure caused by dermal application of over-the-counter Eucalyptus oil head lice preparation. Clin Toxicol 2011;49:750-1.

7. Flaman Z, Pellechia-Clarke S, Bailey B, McGuigan M. Unintentional exposure of young children to camphor and eucalyptus oils. Paediatr Child Health 2001;6:80-3.

8. Low T. Bush Medicine: A Pharmacopoeia of Natural Remedies. Australia: Angus \& Robertson; 1990.

9. Barr A, Knight T, Barr A, Andrews M, Alexander V. Traditional Bush Medicines: An Aboriginal Pharmacopoeia. California: Greenhouse Publications; 1988.

10. Maiden JH. The Forest Flora of New South Wales. Vol. 7. Sydney, Australia: Government Printer; 1908.

11. Whitman BW, Ghazizadeh H. Eucalyptus oil: Therapeutic and toxic aspects of pharmacology in humans and animals. J Paediatr Child Health 1994;30:190a-1.

12. Esmonde-White HP. Eucalyptus oil poisoning. Ind Med Gaz 1898;33:107.

13. Foggie WE. Eucalyptus oil poisoning. Br Med J 1911;1:359-60.

14. Mathew T, Kamath V, Kumar RS, Srinivas M, Hareesh P, Jadav R, et al. Eucalyptus oil inhalation-induced seizure: A novel, underrecognized, preventable cause of acute symptomatic seizure. Epilepsia Open 2017;2:350-4

15. Webb NJ, Pitt WR. Eucalyptus oil poisoning in childhood: 41 cases in South-East Queensland. J Paediatr Child Health 1993;29:368-71.

16. Sitaraman R, Rao G. A pediatric case of accidental Eucalyptus oil poisoning from New Delhi, India: Emergency measures, historical context, and implications for practice. Cureus 2019;11:5734.

17. Fan V, Anand S. The Health Workforce in India. Geneva: World Health Organization 2016. 